\title{
Cartografia do potencial de Au-Pd-Pt e EGP-Cr-Ni na região de Serra Leste (Carajás) utilizando-se a técnica ACP e classificadores hiperespectrais
}

\author{
Thais Andressa Carrino ${ }^{1}$, Carlos Roberto de Souza Filho ${ }^{2}$ \& Emilson Pereira Leite ${ }^{2}$
}

\begin{abstract}
Resumo Este trabalho aborda um estudo sobre a favorabilidade para ocorrência de depósitos de elementos do grupo da platina (EGP) na região de Serra Leste, Província Mineral de Carajás (PA). Esta região é caracterizada por condições atmosféricas adversas e dificuldades de acesso em função da densa floresta equatorial presente. Devido a estas características naturais, dados aerogeofísicos de alta densidade de amostragem foram utilizados em dois estudos de caso associados às mineralizações de EGP: (i) depósito Serra Pelada - um caso particular de ocorrência de Au-Pd-Pt hospedada em rochas metassedimentares; e (ii) depósito Luanga - uma ocorrência clássica de EGP-Cr-Ni hospedada em rochas máficas e ultramáficas. Foram geradas imagens da amplitude do sinal analítico (ASA), dos canais individuais de $\mathrm{K}$, eTh, eU, da contagem total e das razões entre os radioelementos (eU/eTh, K/eTh). Estes produtos interpretativos possibilitaram a individualização dos depósitos Serra Pelada e Luanga por meio da análise de suas respostas magnéticas e radiométricas. Com base nas assinaturas geofísicas e nos modelos descritivos destes dois depósitos minerais, as técnicas Análise por Componentes Principais (ACP), Spectral Angle Mapper e Mixture Tuned Matched Filtering foram aplicadas à base de dados aerogeofísicos, buscando o mapeamento de áreas com características similares aos dos depósitos. Os resultados demonstraram a utilidade destas técnicas de classificação (primeiramente desenvolvidas para processamento de dados de sensores remotos multi e hiperespectrais) para uso estendido aos dados geofísicos aéreos, permitindo o mapeamento de alvos com alta favorabilidade para mineralizações de EGP e outros metais associados, os quais são de interesse geológico, metalogenético e econômico na área de estudo. Ressalta-se que as cautelas necessárias às aplicações da ACP e classificadores hiperespectrais em dados aerogeofísicos, além das vantagens destas técnicas foram discutidas neste estudo de caso.
\end{abstract}

Palavras-chave: geofísica aérea, Análise por Componentes Principais (ACP), classificadores hiperespectrais, Serra Pelada (Au-Pd-Pt), Luanga (EGP-Cr-Ni).

\begin{abstract}
Potential mapping for Au-PGE and PGE-Cr-Ni mineralizations of the Serra Leste region (Carajás) using PCA technique and hiperespectral classifications to airborne geophysical data. This work comprises a study about the favorability for occurrence of Platinum Group Elements (PGE) deposits in the Serra Leste region, Carajás Mineral Province (CMP). This region is characterized by adverse atmospheric conditions and difficulties of access due to presently dense equatorial forest cover. Considering these natural characteristics, high density and resolution airborne geophysical data were utilized in case studies associated to two types of PGE mineralizations: (i) the Serra Leste deposit - a particular case of Au-Pd-Pt hosted by metasediments; and (ii) the Luanga deposit - a classical occurrence of PGE-Cr-Ni hosted by maficultramafic rocks. Maps of the amplitude of the analytic signal, individual $\mathrm{K}, \mathrm{eTh}$, eU, channels, total count and radioelement ratios (eU/eTh, eK/eTh), were generated. These interpretative products enabled the discrimination of the Serra Leste and Luanga deposits by means of the analysis of its magnetic and radiometric signatures. On the basis of the geophysical signatures and descriptive models of these two deposits, Principal Component Analysis (PCA), Spectral Angle Mapper and Mixture Tuned Matched Filtering techniques were applied to the geophysical database, seeking the mapping of areas with similar characteristics to these two deposits. The results showed the utility of these classification techniques (first developed for processing of multispectral and hyperspectral data) for extended use on airborne geophysical data, permitting the mapping of targets more favorable to host PGE deposits, which are of geological, metalogenetic and economic interests in the study area. Although the present testing proved quite promising and advantageous against other techniques, care must be taken to apply such approcahes to geophysical data, an issue also discussed as a topic of this study.
\end{abstract}

Keywords: airborne geophysics, Principal Component Analysis (PCA), hyperspectral classification, Serra Pelada (Au-Pd-Pt), Luanga (PGE-Cr-Ni).

1 - Departamento de Geologia e Recursos Naturais, Instituto de Geociências, Universidade Estadual de Campinas, Campinas (SP.), Brasil. thais.carrino@gmail.com

2 - Departamento de Geologia e Recursos Naturais, Instituto de Geociências, Universidade Estadual de Campinas, Campinas (SP.), Brasil. E-mail: beto@ige.unicamp.br 
INTRODUÇÃO Diversas ambiências geológicas são favoráveis à ocorrência de mineralizações de elementos do grupo da platina (EGP) que compreendem seis elementos químicos: platina $(\mathrm{Pt})$, paládio $(\mathrm{Pd})$, ródio $(\mathrm{Rh})$, rutênio $(\mathrm{Ru})$, ósmio (Os) e irídio (Ir). Os EGP possuem propriedades físico-químicas similares, ocorrendo juntos na natureza e, freqüentemente, associados com ouro e prata, sendo por tal, classificados como metais nobres ou metais preciosos. No cenário econômico mundial, é crescente a demanda por EGP visto a aplicação nas indústrias de tecnologia de ponta, eletroeletrônica, na produção de células de energia, na medicina e no setor joalheiro (Farina 1996). Todo este conjunto de empregos de EGP é decorrente de suas propriedades, tais como altamente refratários, caracterizados por elevados pontos de fusão, altos valores de densidade e atividade catalítica associada (Farina 1996).

Na natureza, os EGP existem na forma de compostos químicos e ligas naturais, totalizando centenas de espécies minerais. Podem-se sintetizar três ambientes mais comuns à ocorrência de depósitos de EGP, juntamente com $\mathrm{Ni}, \mathrm{Cr}, \mathrm{Cu}$ e outros metais: (i) complexos intrusivos acamadados máficos e ultramáficos; (ii) intrusões (sills) com composição de diabásios e gabros, em geral, acamadados; (iii) lavas (intrusões acamadadas), principalmente komatíticas em greenstone belts (Farina 1996).

Cerca de $98,5 \%$ das reservas básicas mundiais de EGP localizam-se na África do Sul (Complexo de Bushveld) e na Rússia (Complexo de Noril'sk). No Brasil, há grandes potencialidades para exploração mineral destes elementos, dado à existência de diversos corpos máficos e ultramáficos atualmente em explotação ou em fase de pesquisa.

Em função dessas perspectivas econômicas, este trabalho ressalta a possibilidade de estudos prospectivos de EGP por meio de um conjunto de técnicas pioneiras para o processamento de dados aerogeofísicos. As técnicas de classificação supervisionada Spectral Angle Mapper (Kruse et al.1993) e Mixture Tuned Matched Filtering (Boardman et al. 1995) são aplicadas rotineiramente para o processamento de imagens hiperespectrais (e.g., Kruse 2003, Cudahy et al. 2004) e multiespectrais (e.g., Souza Filho et al. 2003, Ducart et al. 2006), visando a extração de informações de interesse na exploração mineral. Da mesma forma, a Análise por Componentes Principais (ACP) (e.g., Tangestani \& Moore 2001, Crósta et al. 2003) consiste em um método clássico aplicado a dados de sensoriamento remoto para o mesmo fim. A extensão destes três métodos à aplicação a dados aerogeofísicos para produção de mapas de potencial de EGP e metais associados que possam servir de guias prospectivos para a viabilidade econômica destes compreende o objetivo deste artigo, empregando-se processamentos mais simples se comparados a alguns métodos convencionais de modelagem espacial de dados (e.g., BonhamCarter 1994, Porwal et al. 2003).

A região de Serra Leste, localizada no extremo leste da Serra de Carajás (Fig. 1a), foi selecionada para este estudo demonstrativo em função da disponi- bilidade de dados aerogeofísicos de alta densidade de amostragem e pela existência de dois tipos distintos de estilos mineralizantes, caso de Luanga, um depósito de EGP-Cr-Ni hospedado em rochas máficas e ultramáficas acamadadas e de Serra Pelada, cuja mineralização dominante compreende Au-Pd-Pt hospedada em rochas metassedimentares arqueanas. Esta região está inclusa nos domínios da floresta equatorial ombrófila densa (Floresta Amazônica), caracterizados por intenso intemperismo químico e espessos perfis de solos. A área abrange parte dos municípios de Marabá e Curionópolis, inseridos no sudeste do Estado do Pará. A principal via de acesso compreende a rodovia PA-150 (Fig. 1a).

\section{O CONTEXTO GEOLÓGICO, ESTRUTURAL E} METALOGENÉTICO Localizada no Cráton Amazônico, mais especificadamente no Escudo Guaporé (ou Brasil Central), a região de Serra Leste insere-se no Cinturão de Cisalhamento Itacaiúnas, porção norte da Província Mineral de Carajás (Costa \& Siqueira 1990). Regionalmente, esta região está inclusa no domínio Amazônia Central (> 2,5 Ga) de acordo com Tassinari (1996), ou Carajás (3,0-2,5 Ga) segundo a subdivisão do Cráton Amazônico proveniente do trabalho de Santos et al. (2006).

A figura $1 \mathrm{~b}$ apresenta o mapa geológico esquematizado da região de Serra Leste. De acordo com os trabalhos de Pinheiro \& Holdsworth (2000), Nunes (2002), Tassinari et al. (2000), Villas \& Santos (2001) e Veneziani et al. (2004), o embasamento é dominantemente gnáissico e granitóide, com idade em torno de 2,8 Ga, sendo representado pelo Complexo Xingu. Unidades geológicas dominadas por anfibolitos, xistos, metagrauvacas, litotipos máficos e ultramáficos e formações ferríferas constituem o Grupo Rio Novo (> 2,76 Ga). Datado em torno de 2,76 Ga, o Complexo Luanga é representado por corpos em formato de sills, caracterizados como peridotitos, dunitos, leucogabros e noritos. Quartzitos, metassiltitos carbonosos, metaconglomerados e marga dolomítica, dão representatividade à Formação Águas Claras ( 2,6 Ga). Granitogênese arquena (Granito Estrela, $\sim 2,7 \mathrm{Ga}$ ) e proterozóica anorogênica (Granito Cigano, 1,88 Ga) intrudiram parte das unidades anteriores, da mesma forma que diques proterozóicos e predominantemente gabro-dioríticos. Coberturas recentes constituem as unidades mais jovens, consistindo em superfícies supergênicas e as aluviões.

A região de Carajás foi submetida a três eventos deformacionais principais (Veneziani et al. 2004). $\mathrm{O}$ primeiro evento $(>2,8 \mathrm{Ga})$ relaciona-se à ocorrência de zonas de cisalhamento de direção E-W, envolvendo estruturas transtrativas e terminações 'rabo de cavalo'. O segundo evento $(2,8$ a $2,65 \mathrm{Ga})$ é caracterizado por episódio de cisalhamento transcorrente dextral-oblíquo na direção WNW-ESE, e de natureza rúptil-dúctil a dúctil. O terceiro evento deformacional $(2,6$ a $1,88 \mathrm{Ga})$ é marcado por movimentos transpressivos, também de natureza rúptil-dúctil a dúctil; esse evento foi responsável pela reativação de antigas falhas, com movimentação transcorrente sinistral. A região de Serra Leste 


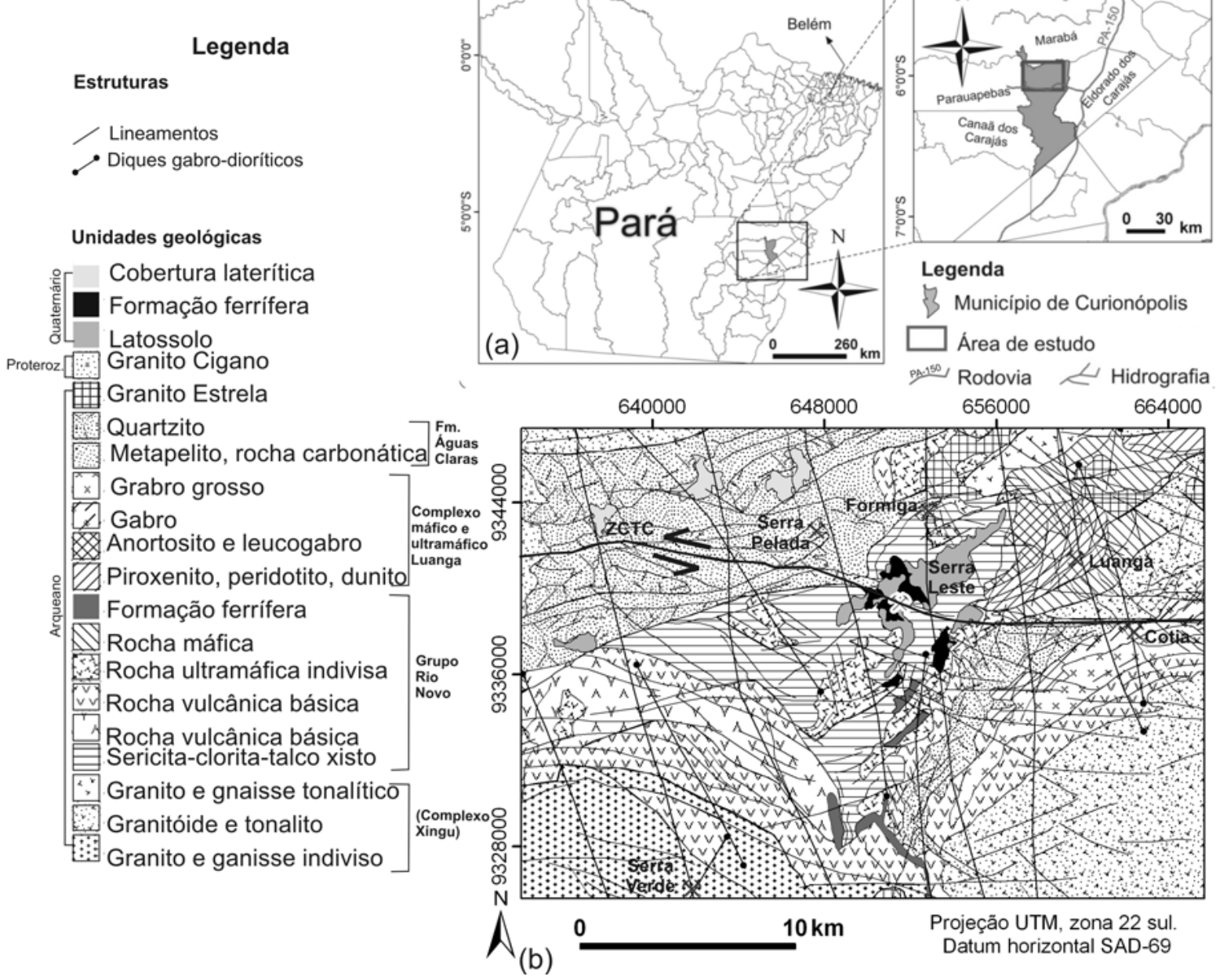

Figura 1 - Localização da área de estudo no sudeste do Estado do Pará (a) e mapa geológico (b) (Veneziani \& Okida inédito, Nunes 2002).

apresenta como principal elemento estrutural a zona de cisalhamento transcorrente Cinzento (ZCTC), caracterizada por movimentação sinistral e direção aproximada E-W, além da terminação 'rabo de cavalo' de Serra Pelada, com direção NE-SW (Costa \& Siqueira 1990, Pinheiro \& Holdsworth 1990) (Fig. 1b).

Serra Leste destaca-se pelo seu potencial à exploração de EGP, sobretudo pela presença de depósitos como o de Luanga (EGP-Cr-Ni) e o de Serra Pelada (Au-Pd-Pt), os quais serão abordados neste estudo. Outros depósitos metálicos também estão compreendidos na área, caso de Serra Verde (Cu-Mo-Au), Serra Leste (Fe), Formiga e Cotia (Au) (Fig. 1b).

O complexo máfico e ultramáfico Luanga compreende corpos de filiação toleítica intrusivos na porção basal do Grupo Rio Novo. A porção inferior é caracterizada por dunitos, peridotitos e ortopiroxenitos (conjunto marcado por presença de magnetita devido a processos de alteração de olivinas), passando a noritos e leucogranitos na parte superior, evidenciando um depósito de filiação magmática estratiforme. Este complexo hospeda um depósito de cromitito deformado e metamorfizado junto às suas rochas encaixantes (Suita 1988), havendo cumulados de platina em noritos. Considerando-se o enriquecimento em EGP, os minerais portadores destes apresentam-se inclusos em cromita, englobados em silicatos serpentinizados e disseminados em ganga silicática alterada em associação com sulfetos (Dardenne $\&$ Schobbenhaus 2001). Os EGP mais comuns correspondem a Pt, $\mathrm{Pd}, \mathrm{Rh}$ e $\mathrm{Ru}$, e, mais raramente, são observados Ir, Os e Re. De acordo com Ferreira Filho et al. (2007), este complexo máfico e ultramáfico também apresenta potencial para mineralizações de $\mathrm{Ni}$.

O depósito Serra Pelada foi intensamente explorado na década de 80 . Este associa-se à última fase tectônica compressiva que afetou a Província Mineral de Carajás, com desenvolvimento de zonas de cisalhamento encaixadas em rochas metassedimentares. Caracteriza-se por um contexto geológico marcado por rochas do Grupo Rio Novo intrudidas pelo Complexo Luanga, e, mais ao topo, seqüências metassedimentares da Formação Águas Claras que compreendem as rochas hospedeiras de $\mathrm{Au}$ Pd-Pt. A mineralização é epigenética e difere dos demais depósitos da província por ser estruturalmente controla- 
da por dobras e falhas, estando contida no flanco de um sinclinal recumbente. O ouro está associado, sobretudo, com paládio (média de 1-10\%), ocorrendo na forma de finas partículas disseminadas em rochas pelíticas e em associação a ambiente de metassomatismo (Villas \& Santos 2001, Cabral et al. 2002). A disposição das mineralizações de ouro segue o contato entre uma marga dolomítica e metassiltitos carbonosos, havendo uma zona silicificada ao redor dos corpos mineralizados. Segundo alguns modelos vigentes, os fluidos hidrotermais teriam interagido com a marga dolomítica e intrusões dioríticas, resultando na precipitação de sulfetos disseminados. Estas intrusões dioríticas ou mesmo as rochas máficas e ultramáficas são postuladas como possíveis fontes de EGP (Tallarico et al. 2000).

MATERIAIS Dados aerogeofísicos (magnetométricos e gamaespectrométricos), caracterizados por linhas de vôo de direção N-S com espaçamento de $250 \mathrm{~m}$ entre elas e provenientes de levantamentos realizados para a Vale, foram selecionados ao estudo.Os dados gamaespectrométricos foram gerados no aerolevantamento de 1993 da Geomag, caracterizado por espaçamento das linhas de controle de $5000 \mathrm{~m}$ na direção E-W. O levantamento foi realizado por meio de um helicóptero modelo 212, e com uma altura de 120 metros fixa, cuja trajetória foi controlada por emprego de GPS (Global Positioning System) da Trimble, modelo TANS II. O gamaespectrômetro possui 256 canais espectrais, consistindo em quatro cristais de NaI ativado a tálio, e volume de 1024 polegadas. Os dados magnetométricos foram coletados pela empresa Geoterrex-Dighem em 1999 e são caracterizados por linhas de controle de direção E-W e espaçadas em $6000 \mathrm{~m}$. Empregou-se um magnetômetro CS-2 de vapor de césio com freqüência de amostragem de $10 \mathrm{~Hz}$ em ciclo contínuo e sensibilidade de $0,01 \mathrm{nT}$, acoplado à cauda de uma aeronave. Juntamente foi utilizado um compensador de efeitos de vôo.

Como dados complementares, a imagem de radar de abertura sintética (SAR) do RADARSAT-1 foi selecionada para integração com os resultados provenientes da favorabilidade de EGP obtidos neste artigo. Estes dados são caracterizados por polarização $\mathrm{HH}$, banda $\mathrm{C}$ $(\sim 5,6 \mathrm{~cm})$, visada descendente, ângulo de incidência de $41^{\circ}$ a $44^{\circ}$ (near-far range) e resolução espacial nominal de $10 \mathrm{~m}$. Consistem em uma imagem coletada em $17 \mathrm{de}$ Maio de 2000 no modo Fine Resolution Path Image F3. Dados altimétricos do Shuttle Radar Topography Mission (SRTM) também foram empregados para integrações, e caracterizam-se por resolução espacial aproximada de 90 m. Foram coletados no ano de 2000 por meio da técnica de interferometria de radar a partir do ônibus espacial Endeavour (Rabus et al. 2003).

\section{MÉTODOS DE TRABALHO}

Assinaturas geofísicas das mineralizações de Serra Pelada e Luanga As componentes de longo comprimento de onda do campo magnético foram removidas utilizando-se o modelo do IGRF (International Geomagnetic Reference Field) (Barton et al. 1996), resul- tando no campo magnético anômalo. Testes de diferença quarta e parâmetros P (Blum 1999) foram aplicados para avaliação da distribuição e consistência dos dados. Uma malha regular foi gerada através da interpolação dos dados pelo método da curvatura mínima, com espaçamento entre os pontos interpolados equivalendo a $1 / 4$ do espaçamento entre as linhas de vôo (62,5 metros) (Vasconcellos et al. 1994).

O micronivelamento foi realizado pela metodologia descrita em Minty (1991). A partir dos dados interpolados e corrigidos foram calculadas as derivadas horizontais em x e y (DX e DY) e a derivada vertical (DZ) para geração da imagem de amplitude do sinal analítico (ASA) (Roest et al. 1992). A ASA é diretamente proporcional à amplitude da magnetização e compreende uma função simétrica em que os picos do sinal analítico encontram-se centrados nas bordas das anomalias magnéticas (Milligan \& Gunn 1997, Nabighian et al. 2005). Regiões com altos valores da ASA foram detectadas nesta imagem, possibilitando a delimitação de corpos com altas amplitudes, muitos dos quais relacionados a unidades máficas e ultramáficas que são possíveis fontes ou rochas hospedeiras de EGP na região (Fig. 2a).

Os dados gamaespectrométricos foram interpolados e micronivelados de maneira análoga aos dados magnetométricos. Destes procedimentos resultaram imagens corrigidas dos canais do $\mathrm{K}$, eTh, eU e da contagem total, além de razões eU/eTh e K/eTh. Imagens ternárias em RGB (vermelho-verde-azul) e CMY (ciano-magenta-amarelo) foram produzidas a partir dos dados dos canais de $\mathrm{K}$, eTh, eU, respectivamente, no intuito de facilitar a delimitação de unidades geofísicas correlacionáveis aos litotipos já pré-mapeados na região de Serra Leste. A figura $2 b$ apresenta a interpretação visual de baixos valores dos radioelementos $\mathrm{K}$, eTh e eU, e à qual assume-se a abrangência de rochas de composição máfica e ultramáfica.

Assinaturas geofísicas relacionadas às ocorrências documentadas de Luanga e Serra Pelada foram quantificadas a partir da seleção das seguintes imagens geofísicas: ASA, K, eTh, eU, contagem total, e razões $\mathrm{eU} / \mathrm{eTh}, \mathrm{K} / \mathrm{eTh}$. Estas imagens, caracterizadas por distintas unidades de medidas, foram re-escalonadas para o formato de 8 bits, a fim de manter a integridade dos dados. O passo seguinte consistiu na extração das assinaturas geofísicas por meio da seleção do pixel, caracterizado por tamanho de $62,5 \mathrm{~m}$, referente às ocorrências georreferenciadas de Au-Pd-Pt (Serra Pelada) e de EGPCr-Ni (Luanga). A figura 3 apresenta a quantificação das assinaturas geofísicas características destas duas ocorrências minerais. Estas assinaturas, magnéticas e radiométricas, são determinadas em função de níveis de cinza, ou DNs (Digital Numbers), variando de 0 (menor valor da assinatura geofísica) a 255 (maior valor).

A partir dos produtos magnetométricos e gamaespectrométricos (Fig. 2) e das assinaturas geofísicas (Fig. 3), as principais características que individualizam os depósitos Luanga e Serra Pelada foram verificadas:

(i) assinaturas geofísicas clássicas de rochas hospedeiras máficas e ultramáficas de EGP-Cr-Ni do de- 

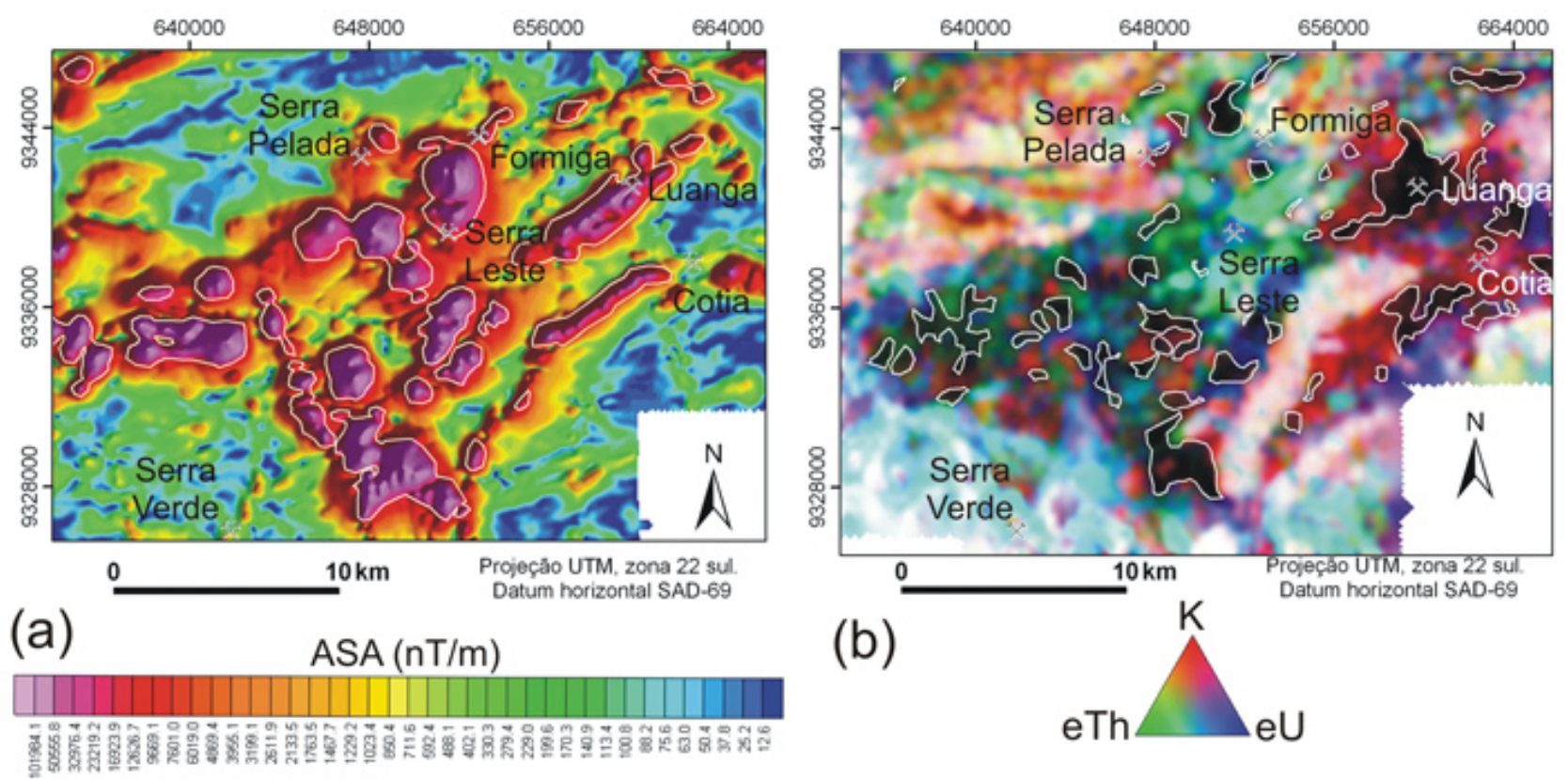

Figura 2 - Imagens geofísicas da região de Serra Leste. (a) imagem da amplitude do sinal analítico (ASA), na qual foram delimitadas regiões com altos valores (contornos em branco). (b) Imagem ternária dos canais de $K$, eTh, eU em $R G B$, a partir da qual foi possível discriminar, qualitativamente, unidades gamaespectrométricas relacionadas a rochas máficas e ultramáficas (contornos em branco).

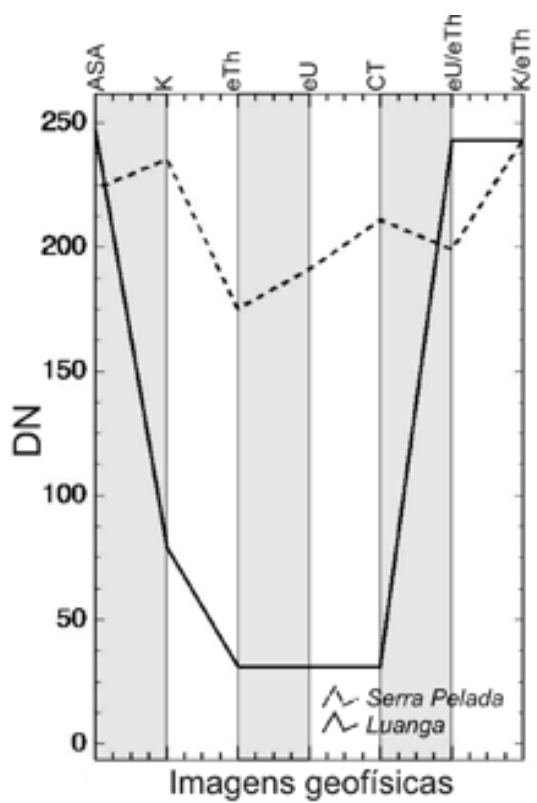

Figura 3 - Assinaturas geofisicas dos depósitos Luanga e Serra Pelada.

pósito Luanga, com baixos valores nos canais radiométricos (Fig. 2 (b)), além de valores considerados muito altos da ASA devido à composição destes litotipos (e.g., olivinas, piroxênios) e suas alterações (e.g., olivinas alteradas para magnetita) (Fig. 2a). Na imagem ternária (Fig. 2b) foram delimitados os baixos valores de K, eTh e eU (linha branca), assinatura esta típica de litotipos de composição máfica a ultramáfica, como já reportado em Dickson \& Scott (1997). Este domínio foi interpretado e correlacionado com a disposição espacial de corpos geológicos do Complexo Luanga e, subordinadamente, às rochas máficas do Grupo Rio Novo (cf., Fig. 1b). Com referência às razões dos radioelementos, altos valores de $\mathrm{K} / \mathrm{eTh}$ e eU/eTh foram constatados (Fig. 3);

(ii) o domínio do depósito Serra Pelada é caracterizado por variação dos valores dos canais radiométricos e das razões destes, além de altos valores da ASA (Figs. 2 e 3). Esta última resposta é decorrente da proximidade de corpos de composição máfica nas porções nordeste e noroeste do depósito, possíveis fonte de EGP em Serra Pelada (e.g., Tallarico et al. 2000, Nunes 2002). Estes corpos estão indicados na figura 2 (a).

Essas constatações das respostas geofísicas e suas relações com a gênese de cada um dos tipos de depósitos aqui abordados justificam a importância destas imagens a fim da determinação de modelos prospectivos para EGP e outros metais relacionados na região de Serra Leste. Desta maneira, as sete imagens geofísicas que individualizam os depósitos do tipo Luanga e Serra Pelada (cf., Fig. 3) foram utilizadas na seleção de alvos potenciais a partir dos métodos abordados a seguir.

Seleção de alvos com base na Análise por Componentes Principais Análise por Componentes Principais (ACP) baseia-se na escolha de $N$ imagens que representam grandezas físicas distintas (e.g., dados geofísicos) ou uma mesma grandeza física, porém, em intervalos diferentes de freqüência (e.g., dados hiperespectrais). Consiste em uma técnica aplicada com a 
finalidade de tornar tais grandezas decorrelacionadas entre si (Drury 2001). Inicialmente, a origem da distribuição dos dados das $N$ imagens é definida como sendo o valor médio do conjunto de dados. As $N$ imagens de tamanho $M=N x$. Ny são transformadas em vetores 1 $\mathrm{x} M$, que são armazenados em uma única matriz $\mathrm{D}$ de tamanho $N$ x $M$. A matriz de covariância $\mathrm{C}=\mathrm{D} \cdot \mathrm{D}^{\mathrm{T}}$ dos dados é decomposta na forma $\mathrm{C}=\mathrm{VUV}^{\mathrm{T}}$, onde $\mathrm{U}$ é uma matriz diagonal $N$ x $N$, cujos elementos da diagonal são os auto-valores de C. A matriz $\mathrm{V}$, de tamanho $N$ x $N$, contém em cada linha os autovetores de C. A operação $\mathrm{V}^{\mathrm{T}} \mathrm{D}$, resulta em uma matriz $N$ x $N x . N y$ de Componentes Principais (CPs), que representa a projeção dos dados originais $\mathrm{D}$ ao longo dos eixos definidos pelos autovetores de C. Os autovalores de cada CP indicam a variância dos dados que são representados pela $\mathrm{CP}$, sendo que quanto maior o autovalor, maior o grau de correlação entre os dados. Os autovetores representam a contribuição de cada imagem original à cada $\mathrm{CP}$ e podem ser positivos ou negativos devido ao reposicionamento da origem da distribuição das $N$ imagens (Drury 2001). Esta técnica é comumente utilizada em imagens multi e hiperespectrais para a exploração mineral, por ser uma ferramenta robusta e de fácil aplicação (e.g., Tangestani \& Moore 2001, 2002, Crósta et al. 2003). Como cada $\mathrm{CP}$ resultante representa uma adição ponderada pelo respectivo coeficiente da matriz de autovetores das bandas originais, é possível selecionar a $\mathrm{CP}$ que contém a informação sobre o alvo, e que está associada a valores mais altos dos autovetores específicos, com sinais positivos ou mesmo negativos.

$\mathrm{O}$ uso da técnica ACP em dados aerogeofísicos, combinados ou não com outros dados multifonte, consta em trabalhos como os de Ranjbar et al. (2003). No presente artigo, o objetivo da aplicação da ACP visa a determinação de alvos máficos e/ou ultramáficos que possam estar relacionados àquelas que hospedam as mineralizações de EGP, além de Cr e/ou Ni. Neste sentido, e utilizando como guia prospectivo as respostas geofísicas típicas do depósito Luanga (Fig.3), a identificação de tais alvos baseou-se nas seguintes contribuições de conjuntos de imagens contrastantes, anteriormente reescalonadas ao formato de 8 bits: altos valores da ASA e das razões $\mathrm{K} / \mathrm{eTh}$ e eU/eTh; baixos valores nos canais de $\mathrm{K}$, eTh, eU e contagem total.

O processamento dessas sete imagens geofísicas foi realizado por meio do uso de matriz de covariância para a geração dos autovetores, como apresentado na tabela 1 .

Na tabela 1, verifica-se que a primeira componente principal (CP1) é caracteriza por maiores contribuições das imagens dos canais de $\mathrm{K}$, eTh, eU, contagem total se comparadas com aquelas referentes à ASA e às razões eU/eTh e K/eTh, por meio da análise dos autovetores. Também pode-se constatar os valores positivos dos autovetores associados às imagens da ASA e das razões de radioelementos, e valores negativos relacionados às imagens dos canais de $\mathrm{K}$, eTh, eU e da contagem total. Esta CP foi escolhida por conter informação característica do alvo objetivado (no caso, rochas máficas e ultramáficas) pela análise da contribuição das imagens geofísicas originais nesta CP e pela observação da disposição dos sinais positivos e negativos dos autovetores, que condizem com o modelo descritivo típico de tais litotipos.

O resultado da ACP é mostrado na Fig. 4, com a imagem da CP1 em tons de cinza e com o histograma ajustado. Os complexos máficos e ultramáficos reconhecidos na região estão numerados como consultado em Nunes (2002): 1 - Luanga Norte; 2 - Luanga; 3 - Luanga Sul; 4 -Afrodite; 5 - Órion; 6 - Formiga; 7 - Pégasus.

Uso de classificadores hiperespectrais Dois algoritmos originalmente desenvolvidos para classificação supervisionada de dados hiperespectrais foram aplicados aos dados geofísicos aéreos da região de Serra Leste: o Spectral Angle Mapper (SAM) e o Mixture Tuned Matched Filtering (MTMF). Diferentemente da técnica ACP, o SAM e o MTMF somente recentemente vêm sendo utilizados e testados em dados aerogeofísicos para seleção de alvos prospectivos. Dentre as principais metodologias já desenvolvidas encontram-se trabalhos de

Tabela 1 - Autovetores derivados da ACP com uso das imagens da amplitude do sinal analítico (ASA), dos canais de K, eTh, eU e da contagem total (CT) e das razões eU/eTh e K/eTh. Destaque à CP1.

\begin{tabular}{l|c|c|c|c|c|c|c}
\hline & ASA & $\mathrm{K}$ & $\mathrm{eTh}$ & $\mathrm{eU}$ & $\mathrm{CT}$ & $\mathrm{eU} / \mathrm{eTh}$ & $\mathrm{K} / \mathrm{eTh}$ \\
\hline CP 1 & 0.210091 & -0.383437 & -0.508703 & -0.478239 & -0.532113 & 0.192338 & 0.034754 \\
\hline CP 2 & 0.136517 & -0.485238 & 0.182592 & 0.009437 & 0.013234 & -0.443746 & -0.717909 \\
\hline CP 3 & -0.782335 & 0.093741 & -0.127087 & -0.322941 & -0.137524 & -0.487156 & -0.717909 \\
\hline CP 4 & 0.562657 & 0.306750 & 0.079534 & -0.319417 & 0.006163 & -0.624401 & 0.301752 \\
\hline CP 5 & -0.000259 & -0.442190 & -0.305940 & 0.617410 & -0.043282 & -0.356015 & 0.448391 \\
\hline CP 6 & 0.092028 & 0.536736 & -0.622128 & 0.321486 & -0.112093 & -0.108173 & -0.434491 \\
\hline CP 7 & 0.011169 & -0.176121 & 0.452508 & -0.283429 & 0.826615 & 0.021215 & 0.004474 \\
\hline
\end{tabular}


Miethke et al. (2007), que utilizaram estes dois métodos hiperespectrais para realce de alvos auríferos na porção sul do Cráton do São Francisco, de Zacchi et al. (2007), que mapearam alvos ferríferos potenciais na região do Espinhaço, e de Carrino et al. (2008), que empregaram a classificação SAM para detecção de ferro supergênico no extremo leste de Carajás.

O método classificador SAM consiste em um algoritmo para mapeamento de alvos por meio da similaridade entre dados de referência, comumente referidos nas aplicações em imagens de sensoriamento remoto como endmembers, e dados a serem classificados em uma imagem. Matematicamente, para cada pixel, são extraídos os valores correspondentes de $N$ imagens e armazenados em vetores-teste $T$, de tamanho $1 \times N$. Os endmembers são também representados por vetores $R$ de tamanho 1 $\mathrm{x} N$. A classificação é realizada pixel-a-pixel, com base no valor do arco-coseno $(\alpha)$ do produto escalar entre os vetores $T$ e $R$, normalizado pelo produto de seus respectivos módulos. Quanto menor o valor de $\alpha$ (ângulo de similaridade), maior a semelhança entre $T$ e $R$ (Kruse et al. 1993). Trabalhos como o de Crósta et al. (1998) e Rowan \& Mars (2003) constituem exemplos da aplicação deste método classificador para realce de alvos em imagens de sensoriamento remoto hiperespectrais.

Baseando-se em tais tipos de trabalhos, alguns ajustes da metodologia inicialmente criada para o processamento de imagens de sensoriamento remoto por meio da aplicação do SAM foram realizados neste presente artigo, no intuito de gerar-se mapas de potencial de Au-Pd-Pt (tipo Serra Pelada) e EGP-Cr-Ni (tipo Luanga). Imagens geofísicas aéreas, convertidas ao formato de 8 bits e compreendendo àquelas referentes aos canais de $\mathrm{K}$, eTh, eU, ASA e as razões eU/K, $\mathrm{eTh} / \mathrm{eU}$ foram selecionadas como dados de entrada para aplicação do método classificador. Em contrapartida à utilização de espectros de minerais medidos em laboratório ou provenientes de bibliotecas espectrais como endmembers, por exemplo, as assinaturas geofísicas apresentadas na figura 3 foram assumidas como os dados de referência para a aplicação do SAM.

A aplicação do algoritmo SAM envolveu a determinação do ângulo de similaridade $(\alpha)$ equivalente a 0,11 e 0,10 radianos no caso dos processamentos referentes ao uso, respectivamente, dos endmembers de Luanga e Serra Pelada. Para este último, a técnica foi aplicada na parte noroeste da imagem, onde insere-se o domínio da Formação Águas Claras que abrange as hospedeiras metassedimentares da mineralização de Au-Pd-Pt típica.

Os mesmos dados de entrada e endmembers utilizados na classificação SAM foram empregados na técnica MTMF. Esta técnica consiste em um algoritmo concebido para o mapeamento de abundâncias de endmembers na escala de sub-pixel (Boardman et al. 1995),

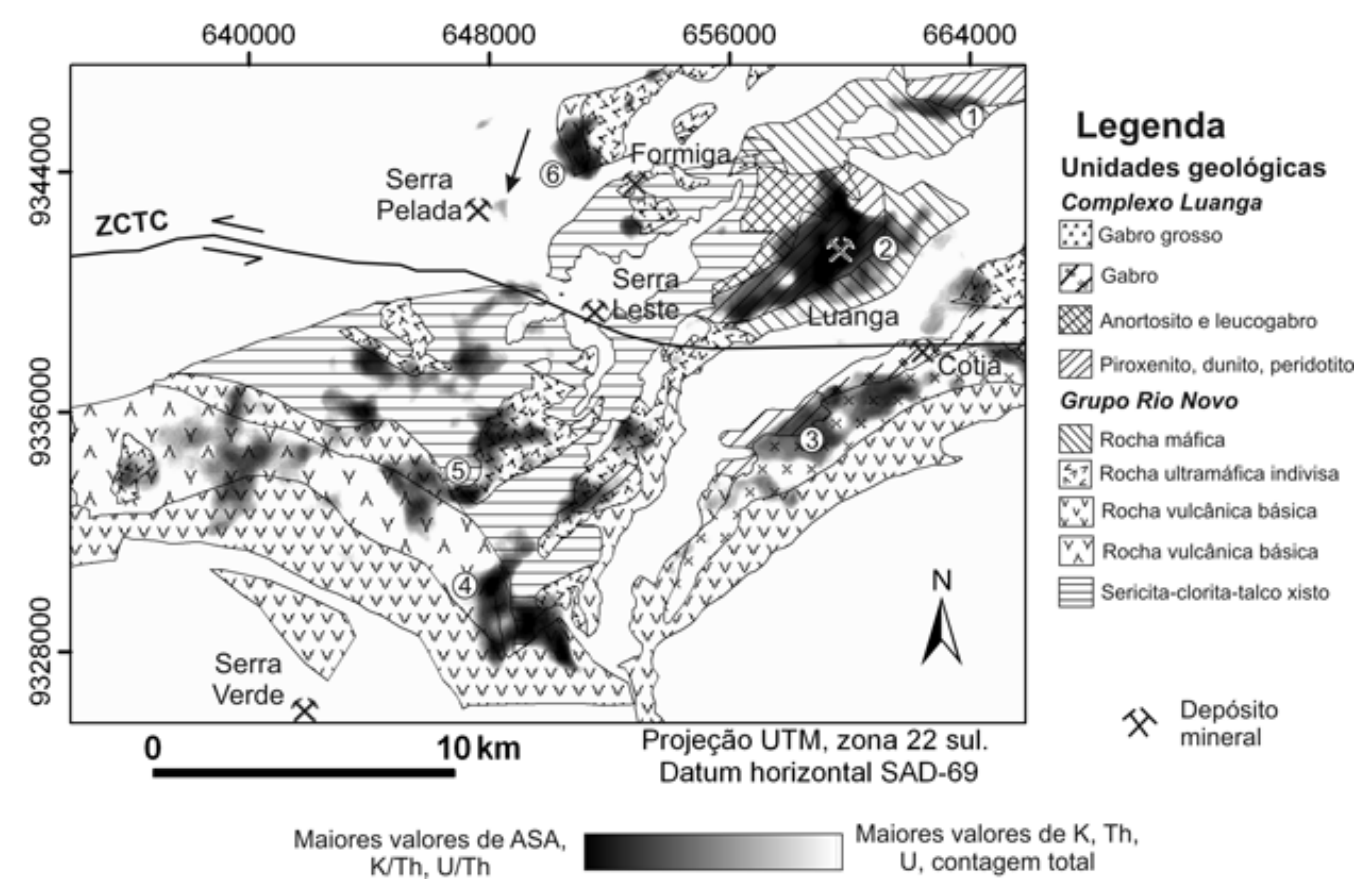

Figura 4 - Resultado da aplicação da ACP mostrando-se a primeira componente principal (CP1) após ajuste de histograma. Pixels escuros associam-se às rochas de composição máfica e ultramáfica da região de Serra Leste e unidades geológicas do Grupo Rio Novo e do Complexo Luanga encontram-se sobrepostas. Corpos máficos e ultramáficos estão indicados de acordo com o trabalho de Nunes (2002). 1 - Luanga Norte; 2 -Luanga; 3 -Luanga Sul; 4 -Afrodite; 5 -Órion; 6 -Formiga; 7 - Pégasus. A seta indica pequeno corpo máfico nas proximidades do depósito Serra Pelada. 
a partir do uso de dois filtros. O Matched Filtering $(M F)$ compreende o filtro de ajuste que maximiza a assinatura do endmember e suprime a resposta do background, proporcionando o discernimento de pixels análogos ao endmember. Em contrapartida, o filtro Mixture Tuned (MT) atua eliminando falsos positivos, ou seja, pixels correspondentes a materiais caracterizados por escores altos, porém com alta improbabilidade de apresentarem assinaturas semelhantes àquelas dos endmembers. Os resultados são obtidos por meio da análise de um diagrama de dispersão composto pelo par escore (eixo x) e improbabilidade (eixo y). Interativamente, foram selecionados os pixels "puros" (coincidentes com o endmember), e que são caracterizados por alto escore e baixa improbabilidade. Trabalhos como de Kruse (2002), Kruse (2003) e Ducart et al. (2006) mostraram bons resultados para realce de alvos mineralizados em metais com base no emprego de imagens de sensoriamento remoto e endmembers compreendendo curvas espectrais de minerais de alterações hidrotermais típicos a cada um dos contextos geológicos.

A partir do processamento realizado com a aplicação do MTMF às imagens geofísicas, os diagramas do tipo escore $v s$. improbabilidade foram produzidos para cada endmember, conforme mostrado na figura 5. Com base nestes diagramas, foram determinados, manualmente, os pixels mais semelhantes à assinatura geofísica de cada ocorrência mineral, ou seja, os pixels "puros". Particularmente, para o depósito Serra Pelada, o mesmo procedimento de classificação da porção noroeste da área de estudo foi adotado para a aplicação deste método classificador.

Os resultados das classificações hiperespectrais para seleção de alvos potenciais análogos ao estilo mineralizante do depósito Luanga estão apresentados na figura 6. Os pixels mapeados pelas técnicas SAM (Fig. 6a) e MTMF (Fig. 6b) foram sobrepostos às unidades máficas e ultramáficas da região de Serra Leste, conforme o mapa geológico da figura 1 (b). Nas figuras 6c, d, os mesmos pixels realçados pelos métodos SAM (a) e MTMF (b), respectivamente, foram sobrepostos ao domínio geofísico de baixos valores nos radioelementos $\mathrm{K}$, eTh e eU, fator característico na determinação espacial de corpos máficos e ultramáficos (cf., Fig. 2 b). Nestas mesmas figuras, observa-se que as regiões classificadas por meio de ambas as técnicas são equivalentes às abrangências dos seguintes corpos máficos e ultramáficos: 1 - Luanga, 2 - Afrodite, 3 - Órion (cf., Nunes 2002).

A figura 7 apresenta os resultados obtidos com as técnicas SAM (a) e MTMF (b) para Serra Pelada, em sobreposição às unidades geológicas da Formação Águas Claras (cf., mapa geológico da Fig. 1b) e à interpretação de unidades gamaespectrométricas com baixos valores de $\mathrm{K}$, eTh, eU.

A figura 8 ilustra os resultados obtidos com a aplicação da técnica SAM, com base no uso dos endmembers relacionados às assinaturas geofísicas dos depósitos Luanga e Serra Pelada, sobrepostos à imagem SAR do RADARSAT-1 integrado ao modelo digital de elevação do SRTM. Os resultados estão visualizados em perspectiva.

DISCUSSÃO DOS RESULTADOS Os resultados das aplicações de técnicas de sensoriamento remoto à aerogeofísica na região de Serra Leste ilustram um conjunto alternativo e robusto de métodos de processamento vinculados à área de prospecção. Neste contexto, a técnica ACP (Fig. 4) e os algoritmos classificadores SAM e MTMF (Fig. 6) revelaram classes similares às assinaturas geofísicas do depósito Luanga, coerentes, de maneira geral, com o domínio das rochas que compõem o Complexo Luanga, destacando-se os litotipos piroxenito, dunito e peridotito. Entretanto, os litotipos de composição máfica do Grupo Rio Novo também foram realçados,
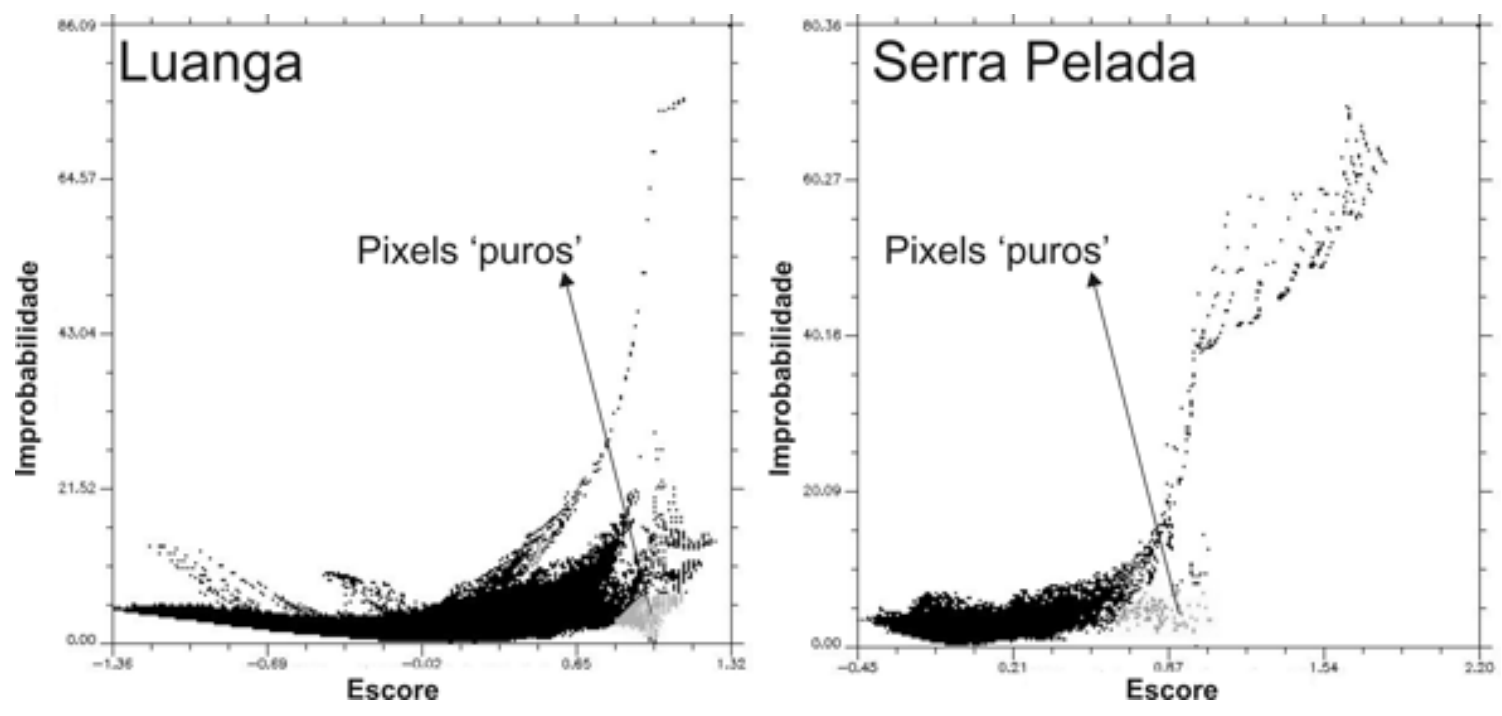

Figura 5 - Diagramas de dispersão (escore vs. improbabilidade) resultantes da aplicação da técnica MTMF, e escolha dos pixels "puros" para os depósitos Luanga e Serra Pelada (endmembers). 

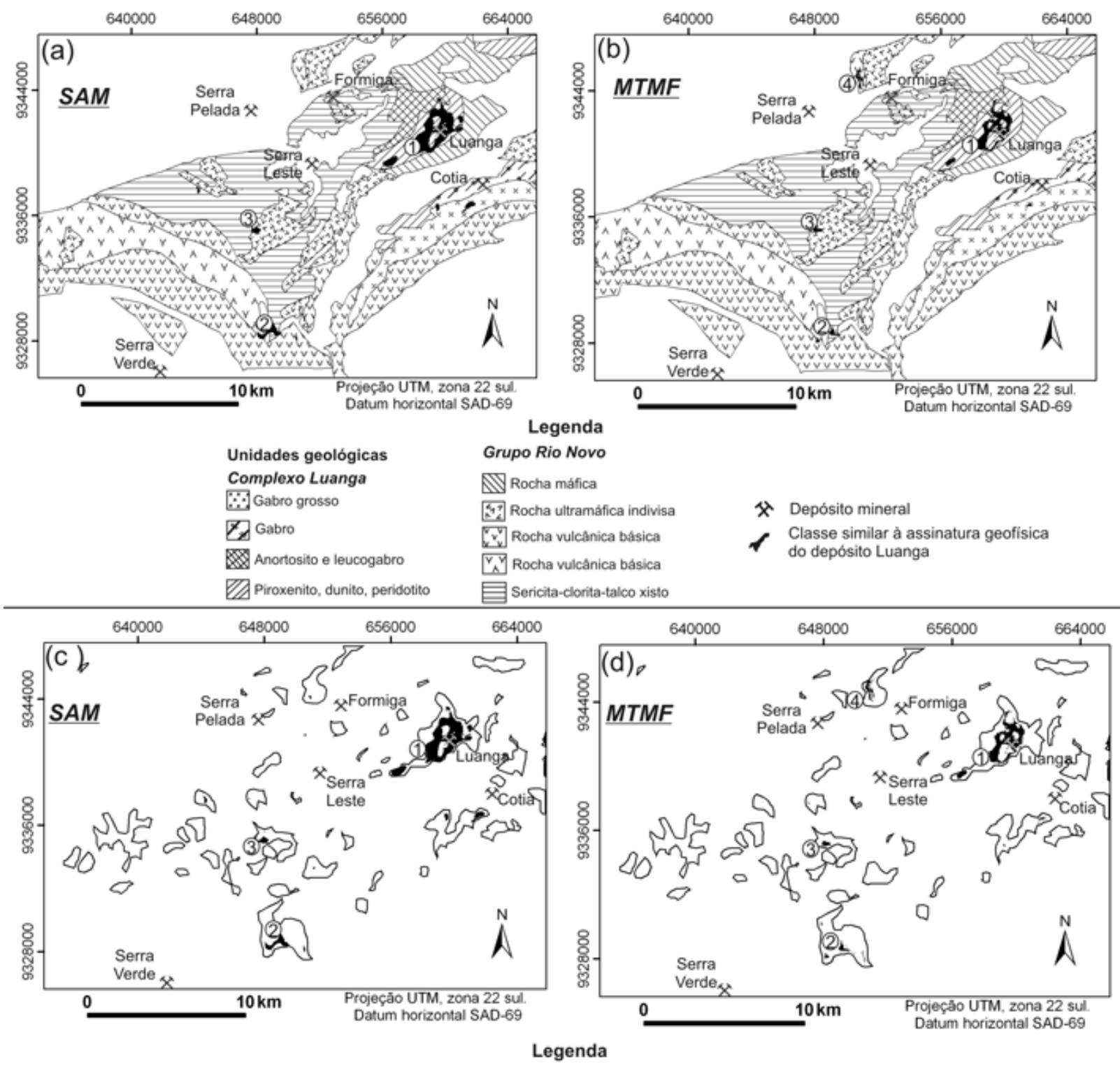

Unidade geofisica referente
a baixos valores nos canais de
$\mathrm{K}$, eTh e eU

x Depósito mineral

Classe similar à assinatura geofisica do depósito Luanga

Figura 6 - Resultados das classificações SAM (a) e MTMF (b) gerados a partir do uso do endmember relacionado às assinaturas geofisicas que caracterizam o depósito Luanga (endmember), sobrepostos às unidades do Complexo Luanga e Grupo Rio Novo (cf., Fig. 1 (b)). As figuras (c) e (d) indicam os mesmos resultados obtidos com as técnicas SAM e MTMF, respectivamente, sobrepostos à unidade gamaespectrométrica marcada por baixos valores de K, eTh e eU (cf., Fig 2 (b)). Corpos máficos e ultramáficos realçados compreendem aqueles indicados em Nunes (2002): 1 -Luanga; 2 -Afrodite; 3 -Órion; 4 -Formiga.

revelando um potencial extensivo para a exploração de EGP-Cr-Ni nestas áreas (cf., Figs. 4 e 6a,b).

A maior parte dos complexos máficos e ultramáficos de que se tem conhecimento na área foram realçados pelas três técnicas utilizadas. Dentre estes, destacaram-se os complexos Luanga, Luanga Sul, Afrodite e Órion (Figs. 4 e 6). A aplicação da ACP (Fig. 4), em particular, revelou a existência de um pequeno corpo máfico e ultramáfico nos arredores de Serra Pelada, outra possível fonte local de EGP, como já postulado por Tallarico et al. (2000) e Nunes (2002) (vide seta na Fig. 4). Nesta mesma imagem, o deslocamento dos corpos Luanga (1) e Luanga Sul (2) ilustra a movimentação transcorrente sinistral decorrente da reativação da ZCTC durante a terceira fase deformacional que afetou a região de Carajás (Veneziani et al. 2004).

A sobreposição das regiões classificadas pelos métodos SAM e MTMF à unidade gamaespectrométrica de baixos valores em K, eTh, eU (Fig. 6), também mostrou resultados satisfatórios e condicionados a estas 


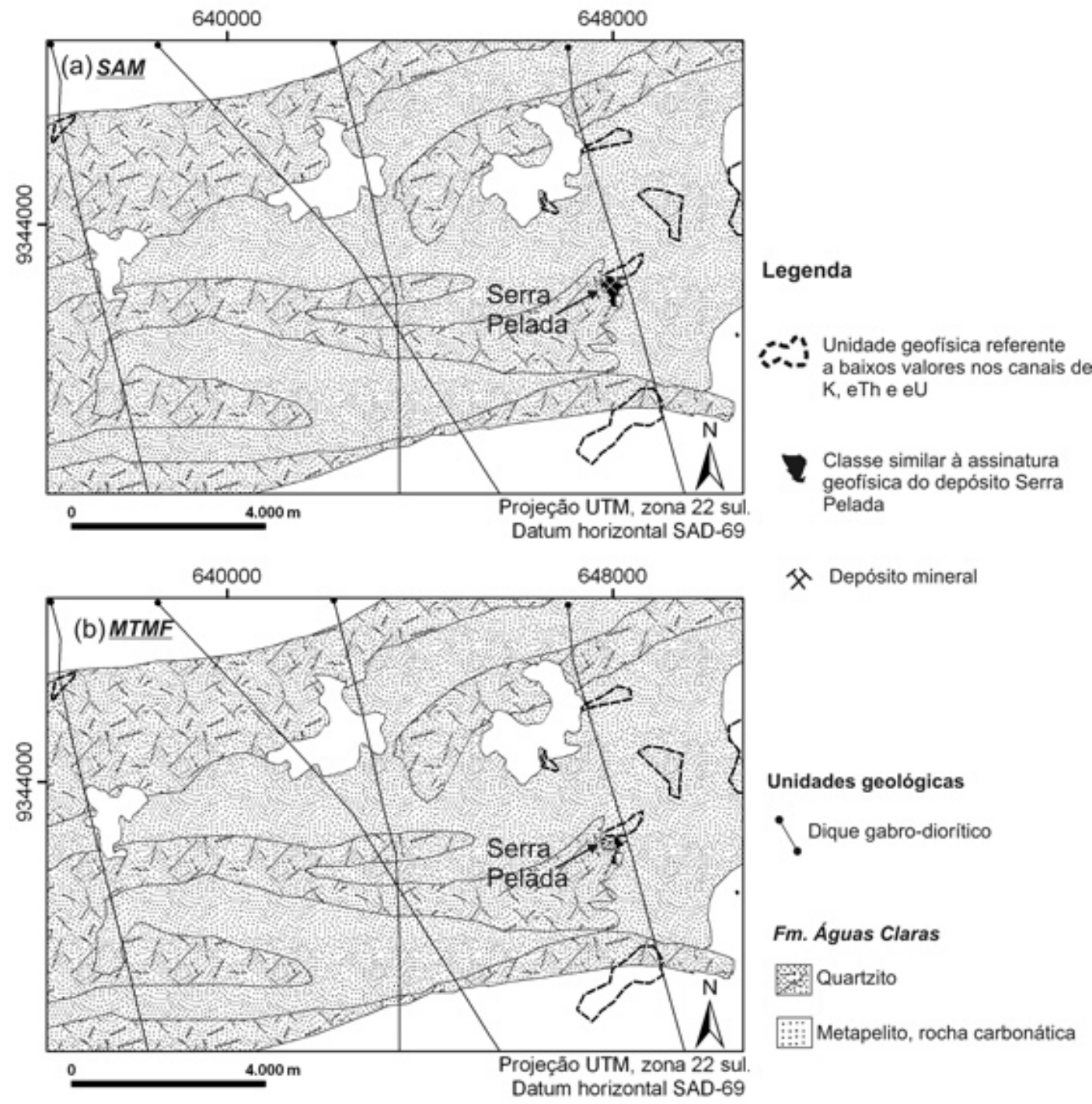

Figura 7 - Resultados das classificações SAM (a) e MTMF (b) produzidos com base no uso do endmember relacionado às assinaturas geofisicas que caracterizam o depósito Serra Pelada, sobrepostos às unidades geológicas da Formação Águas Claras e à unidade gamaespectrométrica de baixos valores em K, eTh e eU (cf., Fig. 1 (b)).

áreas que, por sua vez, estão radiometricamente associadas às rochas de composição máfica e ultramáfica (e.g., Dickson \& Scott 1997). Ressalta-se que a delimitação qualitativa da unidade caracterizada pelos baixos valores nos três radioelementos (Fig. 2b), realizada para uma primeira aproximação ao reconhecimento de litotipos máficos e ultramáficos favoráveis a portarem EGP-Cr-Ni, apresentou alta coerência com a quantificação da assinatura geofísica derivada do endmember associado ao depósito Luanga (Fig. 3).

No caso do depósito Serra Pelada, somente os arredores do mesmo foram classificados pelos métodos SAM e MTMF (Fig. 7). Este fato pode ser explicado por ser este depósito uma particularidade de mineralização do tipo Au-Pd-Pt em toda a Província Mineral de Carajás, hospedado em rochas metassedimentares e associado a processos de alteração hidrotermal (Tallarico et al. 2000). Adicionalmente, é importante notar na figura 7 , que a potencialidade de Au-Pd-Pt mapeada por ambas as técnicas está condicionada à área de influência de um dique gabro-diorítico disposto na direção NNW-SSE, e que compreende outra possibilidade para fonte de EGP (e.g., Tallarico et al. 2000), além da existência de corpos de composição máfica também indicados nesta figura.

A figura 8 permite a visualização, em perspectiva, das áreas realçadas pela técnica SAM considerandose os depósitos Luanga e Serra Pelada. Para o primeiro depósito, foi possível notar que os pixels classificados como corpos potenciais para EGP-Cr-Ni são coerentes, majoritariamente, com regiões mais rebaixadas e erodidas, visto a composição básica das rochas hospedeiras (Complexo Luanga e rochas máficas do Grupo Rio Novo). No caso de Serra Pelada, o alvo classificado está associado à porção noroeste da área de estudo, que compreende uma macrotopografia acidentada com drenagens incisivas, típicas das serras quartzíticas da 


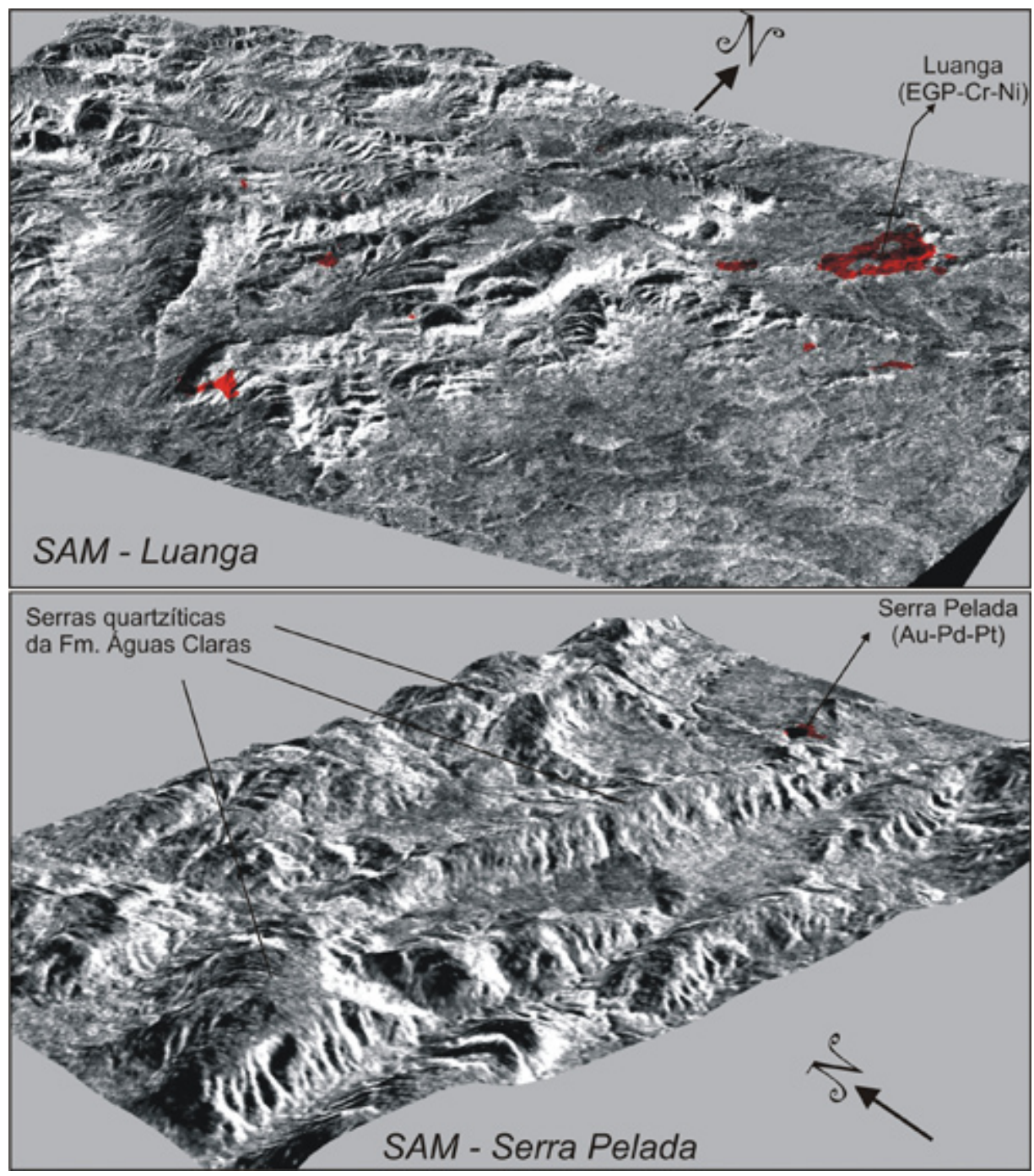

Figura 8 - Resultados das classificações SAM para os depósitos Luanga e Serra Pelada integrados à imagem do RADARSAT-1 e em perspectiva por meio do uso do modelo digital de elevação do SRTM.

Formação Águas Claras em meio a regiões mais planas representantes dos metapelitos hospedeiros de Au-PdPt (cf., mapa geológico da Fig. 1b).

CONCLUSÕES Este estudo demonstrou que técnicas comumente adotadas em sensoriamento remoto, quando aplicadas ao processamento de imagens aerogeofísicas (canais de $\mathrm{K}$, eTh, eU, contagem total, ASA e razões dos radioelementos), permitem a extração de informações geológico-metalogenéticas relevantes, como demonstrado com a classificação pioneira de alvos potenciais para EGP associados a outros metais, na região de Serra Leste, Província Mineral de Carajás. O trabalho conseguiu discriminar as diferentes respostas magnetométricas e radiométricas dos depósitos Serra Pelada e Luanga, utilizando-as como subsídio posterior à classificação de alvos potencialmente mineralizados em Au-Pd-Pt e EGP-Cr$\mathrm{Ni}$, respectivamente. A produção de mapas de potencial desempenha um papel fundamental para a orientação e auxílio de trabalhos de campo a fim da constatação in situ das evidências metalogenéticas que possam viabilizar a exploração mineral.

É importante mencionar que os resultados gerados pela aplicação dessas técnicas foram dependentes do entendimento do modelo descritivo das mineralizações (Au-Pd-Pt e EGP-Cr-Ni) e dos limiares utilizados pelo usuário para determinação da quantidade de pixels classificados, caso do realce proporcionado pela ACP com base no manuseio interativo do histograma (Fig. 4) da escolha dos ângulos de similaridade pelo método SAM (Figs. 6a,c e 7a) e da determinação manual dos pixels mais favoráveis às assinaturas dos depósitos pela técnica MTMF (Figs. 6b,d e 7b). A partir de bom entendimento do modelo genético e dos limiares objetivados, o uso destas três técnicas ao processamento de dados aerogeofísicos mostra a capacidade destas em aplicação a outros contextos metalogenéticos, para geração de mapas de potencial mineral consistentes.

As vantagens da utilização das técnicas ACP, SAM e MTMF também foram observadas. Com os re- 
sultados dos estudos de caso apresentados nesse trabalho, pôde-se perceber que em terrenos tropicais úmidos, técnicas concebidas originalmente para o processamento de dados de sensoriamento remoto são capazes de derivar resultados ainda mais satisfatórios quando aplicados também a dados aerogeofísicos. Este fato é explicado pelo papel que os espessos perfis intempéricos e a densa cobertura vegetal implicam em imagens adquiridas sob estes terrenos, impedindo a interação da energia eletromagnética da região do visível ao infravermelho termal $(\sim 0,38-14 \mu \mathrm{m})$ com o substrato geológico, cujo reconhecimento é fundamental para a seleção de alvos exploratórios. Adicionalmente, a energia captada dos alvos terrestres pelos sensores remotos é fortemente influenciada pela atmosfera, visto pelos fenômenos de espalhamento e absorção de intervalos de energia específicos em função da existência de determinados gases e partículas atmosféricas. Neste sentido, o emprego das técnicas SAM e MTMF em um conjunto selecionado de imagens geofísicas, vantajosamente, não requer um pré-processamento dos dados visando a correção atmosférica, etapa esta indispensável e anterior à aplicação de qualquer método classificador em imagens de sensoriamento remoto multi e hiperespectral.

Agradecimentos T.A. Carrino e E.P. Leite agradecem à FAPESP (Fundação de Amparo à Pesquisa do Estado de São Paulo) pela concessão, respectivamente, da bolsa de iniciação científica (Proc. 2006/02566-8) e da bolsa de pós-doutorado (Proc. 2005/04453-3). C.R. Souza Filho agradece à FAPESP pelo auxílio financeiro à pesquisa (Procs. No. 2003/09916-6 e No. 2002/09038-6) e ao $\mathrm{CNPq}$ pela bolsa de produtividade em pesquisa.

\section{Referências}

Barton C. E., Baldwin R.T., Barracloughd D. R., Bushati S., Chiappini M., Cohen Y., Coleman R., Hulot G., Kotz'e R., Golovkov V. P., Jackson A., Langel R. A., Lowes F. J., Mcknight D. J., Macmillan S., Newitt L. R., Peddien W., Quinn J. M., Sabaka T.J. 1996. International Geomagnetic Reference Field. 1995 Revision. IAGA Division V. Working Group 8, Phys. Earth Planet. Inter., 97:23-26.

Blum M.L.B. 1999. Processamento e interpretação de dados de geofísica aérea no Brasil central e sua aplicação à geologia regional e à prospecção mineral. Tese de Doutoramento, Inst.Geociências, Univ. de Brasília, 229p.

Boardman J.W., Kruse F.A., Green R.O. 1995. Mapping target signatures via partial unmixing of AVIRIS data. In: Annual JPL Airborne Earth Science Workshop, 5, Washington, D.C., Summaries, JPL Publication 95-1,1:23-26.

Bonham-Carter G.F. 1994. Geographic information systems for geoscientists: modelling with GIS. Oxford, Pergamon, 398p.

Cabral A.R., Lehmann B., Kwitko-Ribeiro R., Cravo Costa C.H. 2002. Palladium and platinum minerals from the Serra Pelada Au-Pd-Pt deposit, Carajás Mineral Province, northern Brazil. The Canadian Mineralogist, 40:1451-1463.

Carrino T.A., Souza Filho C.R., Leite E.P. 2008. Processamento e integração de imagens multiespectrais, e radar e aerogeofísicas do Bloco Serra Leste (Carajás, PA) e discussão do potencial para mineralizações de ferro. Revista Brasileira de Geofísica, 26(2):123-140.

Costa J.B.S. \& Siqueira J.B. 1990. Transtração e transpressão ao longo do Lineamento Cinzento (região da Serra dos Carajás). Ver. Bras. Geoc., 20(1-4):234-238.

Crósta A.P., Souza Filho C.R., Azevedo F., Brodie C. 2003. Targeting key alteration minerals in epithermal deposits in Patagonia, Argentina, using ASTER imagery and principal component analysis. International Journal of Remote Sensing, 24(21):4233-4240.

Crósta A.P., Sabine C., Taranik J.V. 1998. Hydrotermal alteration mapping at Bodie,California, using AVIRIS hyperspectral data. Remote Sensing of Environment,
Dardenne M.A. \& Schobbenhaus C. 2001. Metalogênese do Brasil. Brasília-DF, Ed. UnB, 394p.

Dickson B.L. \& Scott K.M. 1997. Interpretation of aerial gamma-ray surveys - adding the geochemical factors. AGSO Journal of Australian Geology \& Geophysics, 17(2): 187-200.

Drury S.A. 2001. Image interpretation in geology. 3 ed., Inglaterra, Blackwell Science, 290p.

Ducart D.F., Crósta A.P., Souza Filho C.R., Coniglio J. 2006. Alteration Mineralogy at the Cerro La Mina Epithermal Prospect, Patagonia, Argentina: Field Mapping, ShortWave Infrared Spectroscopy, and ASTER Images. Economic Geology and the Bulletin of the Society of Economic Geologists, 101:1010-1025.

Farina M. 1996. Programa nacional de prospecção de metais do grupo da platina - uma síntese (Parte 1). A Terra em Revista, 2(1):50-55.

Ferreira Filho C.F., Cançado F., Correa C., Macambira E.M.B., Siepierski L., Junqueira-Brod T.C. 2007. Mineralizações estratiformes de EGP-Ni associados a complexos acamadados em Carajás: os exemplos de Luanga e Serra da Onça. In: Rosa-Costa L.T., Klein E.L., Viglio E.P. (orgs.) Contribuições à Geologia da Amazônia. Belém-PA, Publitec Gráfica \& Editora, 5:1-14.

Kruse F.A. 2003. Mineral Mapping with AVIRIS and EO-1 Hyperion. In: JPL Airborne Geoscience Workshop, $12^{\text {th }}$, Proceedings, Jet Propulsion Laboratory Publication 4-6 (CD-ROM), p.: 149-156.

Kruse F.A. 2002. Comparison of AVIRIS and Hyperion for hyperespectral mineral mapping. In: JPL Airborne Geoscience Workshop, $11^{\text {th }}$, Pasadena (Califórnia), Proceedings, Jet Propulsion Laboratory Publication 3-4 (CDRom).

Kruse F.A., Lefkoff A.B., Boardman J.B., Heidebrecht K.B., Shapiro A.T., Barloon P. J., Goetz A.F.H. 1993. The Spectral Image Processing System (SIPS) - Interactive Visualization and Analysis of Imaging Spectrometer Data. Remote Sensing of Environment, 44:145-163.

Miethke C., Souza Filho C.R., Silva A.M. 2007. Assinatura geofísica e modelos prospectivos 'knowledge-driven' de mineralizações de $\mathrm{Au}$ no lineamento Congonhas, sul do Revista Brasileira de Geociências, volume 38 (3), 2008 
Cráton São Francisco, MG. Revista Brasileira de Geociências, 37(3):490-503.

Milligan P.R. \& Gunn P.J. 1997. Enhancement and presentation of airbone geophysical data. AGSO Journal of Australian Geology \& Geophysics, 17(2):63-75.

Minty B.R.S. 1991. Simple micro-levelling for aeromagnetic data. Exploration Geophysics, 22:591-592.

Nunes A.R. 2002. Análise de dados geológicos, geofísicos $e$ de sensoriamento remoto para geração de modelos prospectivos para a região de Serra Leste, Carajás (PA). Dissertação de Mestrado, Instituto de Geociências, Universidade Estadual de Campinas, 132p.

Pinheiro R.V. \& Holdsworth R. 2000. Evolução tectonoestratigráfica dos sistemas transcorrentes Carajás e Cinzento, Cinturão Itacaiúnas, borda leste do cráton Amazônico, Pará. Rev. Bras. Geoc., 30(4):597-606.

Porwal A., Carranza E.J.M., Hale M. 2003. Knowledgedriven and data-driven fuzzy models for predictive mineral potential mapping. Natural Resources Research, 12(1):1-25.

Rabus B., Eineder M., Roth A., Bamler R. 2003. The shuttle radar topography mission - A new class of digital elevation models acquired by spaceborne radar. Journal of Photogrammetry \& Remote Sensing, 57:241-262.

Ranjbar H., Honarmand M., Moezifar Z., Shakoori M. 2003. Integration and analysis of remote sensing, airborne geophysics and geochemical data of Sar Cheshmeh area, using directed principal component analysis. In: Remote sensing for environmental monitoring, GIS applications, and geology, 2, Agia Pelagia-Greece, Proceedings, 4886:429-437.

Roest W.R., Verhoef J., Pilkington M. 1992. Magnetic interpretation using the 3-D analytic signal. Geophysics, 57(1):116-125.

Rowan L.C. \& Mars J.C. 2003. Lithologic mapping in the Mountain Pass, California area using Advanced Spaceborne Thermal Emission and Reflection Radiometer (ASTER) data. Remote Sensing of Environment, 84:350366.

Santos J.O.S., Hartmann L.A., Riker S.R., Souza M.M., Almeida M.E., Mcnaughton N.J. 2006. A compartimentação do cráton Amazonas em províncias: avanços ocorridos no período 2000-2006. In: SBG, Simp. Geol. Amazônia, 9, Atas, 4 p, CD-R.

Souza Filho C.R., Tapia C.H.C., Crósta A.P., Xavier R.P. 2003. Infrared spectroscopy and ASTER imagery analysis of hydrothermal alteration zones at the Quellaveco porphyry-copper deposit, southern Peru. In: American Society for Photogrammetry and Remote Sensing (ASPRS), Annual Conference, Proceedings, p.1-12 (CD-
Rom).

Suita M.T.F. 1988. Geologia da área Luanga com ênfase na petrologia do complexo básico-ultrabásico Luanga e depósitos de cromita associados, Pará. Dissertação de Mestrado, Inst. Geociências, Univ. de Brasília, 320p.

Tallarico F.H.B., Coimbra C.R., Costa C.H.C. 2000. The Serra Leste sediment-hosted Au-(Pd-Pt) mineralization, Carajás Province. Rev. Bras. Geoc., 30(2):226-229.

Tangestani M. H. \& Moore F. 2002. Porphyry copper alteration mapping at the Meiduk area, Iran. International Journal of Remote Sensing, 23:4815-4826.

Tangestani M.H. \& Moore F. 2001. Comparision of three principal component analysis techniques for porphyry cooper alteration mapping: a case study in Meiduk area, Kerman, Iran. Canadian Journal of Remote Sensing, 27:176-182.

Tassinari C.C.G., Bettencourt J.S., Geraldes M.C., Macambira M.J.B., Lafon J.M. 2000. The Amazonian Craton. In: Cordani J.G., Milani E.J., Campos D.A. (orgs.) Tectonic evolution of South America. In: International Geological Congress, 31 ${ }^{\text {st }}$, Rio de Janeiro-RJ, p. 41-95.

Tassinari C.G.C. 1996. O mapa geocronológico do cráton amazônico no Brasil: revisão dos dados isotópicos. Tese de livre docência, Instituto de Geociências, Universidade de São Paulo, 139p.

Vasconcellos R.M., Metelo M.J., Motta A.C., Gomes R.D. 1994. Geofísica em levantamentos geológicos no Brasil. Rio de Janeiro, CPRM, 165 p.

Veneziani P., Santos A.R., Paradella W.R. 2004. A evolução tectono-estratigráfica da Província Mineral de Carajás: um modelo com base em dados de sensores remotos orbitais (SAR-C RADARSAT-1, TM LANDSAT-5), aerogeofísica e dados de campo. Rev. Bras. Geoc., 34(1):6778.

Villas R.N. \& Santos M.D. 2001. Gold deposits of the Carajás mineral province: deposit type and metallogenesis. Mineralium Deposita, 36:300-331.

Zacchi E.N.P., Silva A.M., Rolim V.K., Portugal R.S. 2007. Aplicação de técnicas de sensores remotos multiespectrais e hiperespectrais em dados aerogeofísicos visando a seleção de alvos para a prospecção de minério de ferro na Serra do Espinhaço Meridional, MG. In: Congress of the Brazilian Geophysical Society \& EXPOGEF, 10, Rio de Janeiro-RJ, Summary, CD-Rom.

Manuscrito ID 11101 Submetido em 13 de abril de 2008 Aceito em 20 de setembro de 2008 Sistema eletrônico de submissão 